\title{
Large-scale observations of alpine snow and ice cover in Asia: Using multi-temporal VEGETATION sensor data
}

\author{
X. XIAO,†† B. MOORE III, $\uparrow$ X. QIN,§ Z. SHEN $\|$ and \\ STEPHEN BOLES $\dagger$ \\ $†$ Complex Systems Research Center, Institute for the Study of Earth, Oceans \\ and Space, University of New Hampshire, Durham, NH 03824, USA \\ $\$$ Institute of Geographical Science and Natural Resources, Chinese Academy of \\ Sciences, Beijing, 100101, China; xiangming.xiao@unh.edu \\ §Institute of Geology, Chinese Academy of Sciences, Beijing, 100029, China
}

(Received 6 March 2000; in final form 13 March 2001)

\begin{abstract}
In this study we used twenty-five 10-day synthetic products (composites) of the VEGETATION (VGT) sensor on SPOT 4 satellite from 11-20 March 1999 to 11-20 November 1999 to map snow and ice cover at 1-km spatial resolution in an alpine environment of Asia. The study area is within $73^{\circ}-103^{\circ} \mathrm{E}$ and $25^{\circ}-40^{\circ} \mathrm{N}$ (a total land area of 4.7 million $\mathrm{km}^{2}$ ), and includes the highest alpine region in the world (e.g. Himalaya Mountains, Qinghai-Tibet Plateau, Pamirs Plateau, Karakoram Range). In the VGT-based mapping approach, the Normalized Difference Snow/Ice Index (NDSII) is calculated as $\mathrm{NDSII}=(\mathrm{B} 2-\mathrm{MIR}) /(\mathrm{B} 2+\mathrm{MIR})$, where the ground reflectance values of the red band (VGT band B2) and the mid-infrared band (VGT band MIR) are used. When NDSII and the reflectance value of the near-infrared band (VGT band B3) in a pixel $(1 \mathrm{~km} \times 1 \mathrm{~km})$ meet the thresholds of NDSII $\geqslant 0.40$ and band $\mathrm{B} 3>0.11$, the pixel is assigned to be snow/ice cover. Total areas of snow/ice cover in the alpine region had large seasonal variations, ranging from 0.46 million $\mathrm{km}^{2}$ in 11-20 March 1999 to 0.05 million $\mathrm{km}^{2}$ in 1-10 August 1999 to 0.60 million km² in 11-20 November 1999. Spatial distributions of snow/ice cover also varied substantially across the alpine region. There were large areas of snow/ice cover in the north-western part of the alpine region in March and April, but large areas of snow/ice cover in the eastern part of the alpine region in October and November. Qualitatively, spatial patterns and temporal dynamics of snow/ice cover in the alpine region are closely correlated to the plateau monsoon climate and its precipitation patterns.
\end{abstract}

\section{Introduction}

In addition to snow and ice cover in the high latitudes and the polar areas, snow and ice cover is also widely distributed in mountains and plateaus. Mountainous lands account for about $20 \%$ of the Earth's terrestrial surface and about $10 \%$ of the world population lives there (Ives and Messerli 1999). Snow and ice cover in

|| Northwest Plateau Institute of Biology, Chinese Academy of Sciences, Xining, Qinghai, Province, 810001, China. 
mountains and plateaus is characterized by rapid seasonal changes, and it plays an important role in regional climate and water resources (Goodison et al. 1999). To date, large-scale (continental to global) operational mapping and monitoring of snow and ice cover has been largely dependent on the Advanced Very High Resolution Radiometer (AVHRR) data (Robinson et al. 1993, Xu et al. 1993, Ramsay 1998, Cline and Carroll 1999, Romanov et al. 2000). Existing snow/ice cover datasets are generally at very coarse spatial resolution. For instance, an AVHRR-based database has archived the records of snow cover for the globe from 1972 at a weekly interval, but at a very coarse (190.5-k m polar stereographic grid) spatial resolution (Robinson et al. 1993). Ramsay (1998) provided an AVHRR-based snow and ice cover dataset for the Northern Hemisphere at a weekly interval and with a $25-\mathrm{km}$ spatial resolution. Romanov et al. (2000) provided a snow cover dataset for North America at a daily interval and with a 4-km spatial resolution, using multiple spectral sensors (AVHRR, GOES, DMSP SSM/I). Cline and Carroll (1999) generated a snow cover dataset for the continental USA at 5-day/weekly intervals and with a 1-km spatial resolution, using AVHRR and GOES images.

The SPOT 4 satellite, which was launched in March 1998, carries the VEGETATION (VGT) sensor that is one of a new generation of optical sensors designed for studying the land surface and vegetation. In comparison with the NOAA AVHRR sensors, which were originally designed for meteorological observations, the VGT sensor has a number of improved and unique characteristics. For example, it has four spectral bands (blue, red, near-infrared, mid-infrared) that are equivalent to Landsat Thematic Mapper (TM band 1, 3, 4, 5). It acquires images at a spatial resolution of $1.15-\mathrm{km}$ at nadir in both directions and provides image coverage of the globe within 1-2 days. Therefore, VGT data may offer a new opportunity for operational mapping and monitoring of snow and ice cover across large spatial scales from continent to the globe at $1-\mathrm{km}$ spatial resolution.

In this study we used multi-temporal VGT data in 1999 to characterize the spatial distribution and seasonal dynamics of snow and ice cover in an alpine region of Asia $\left(73^{\circ}-103^{\circ} \mathrm{E}\right.$ and $25^{\circ}-40^{\circ} \mathrm{N}$, a total land area of 4.7 million $\left.\mathrm{km}^{2}\right)$. The study area contains the largest mountains and highest plateaus in the world (figure 1), including the Himalaya Mountains, the Quinghai-Xizang (Tibet) Plateau in China, the Pamirs Plateau, and Karakoram Range. The Qinghai-Xizang Plateau is sometimes called the 'world roof' or 'third pole' because of its high elevation (mostly over $4000 \mathrm{~m}$ above sea level). Some of the largest rivers in the world originate in the alpine region, e.g. the Yellow River in China. The objective of this study is two-fold: (1) to develop an approach that is simple and potentially useful for operational mapping of snow and ice cover, based on VGT sensor data; and (2) to provide a database of snow and ice cover at $1-\mathrm{km}$ spatial resolution for the alpine region in Asia. A dataset that describes the spatial distribution and seasonal dynamics of snow and ice cover in the alpine region is critically needed by the climate and hydrological modelling communities as well as for water resource management (Zhen and Li 1998).

\section{Data and methods}

\subsection{Multi-temporal VEGETATION (VGT) data}

Three types of standard VGT products are provided to users: VGT-P (physical product), VGT-S1 (daily synthesis) and VGT-S10 (10-day synthesis). In the VGT-S (S1, S10) products, selection of pixels for synthesis is based on the maximum Normalized Difference Vegetation Index (NDVI) value, so that it ensures global 


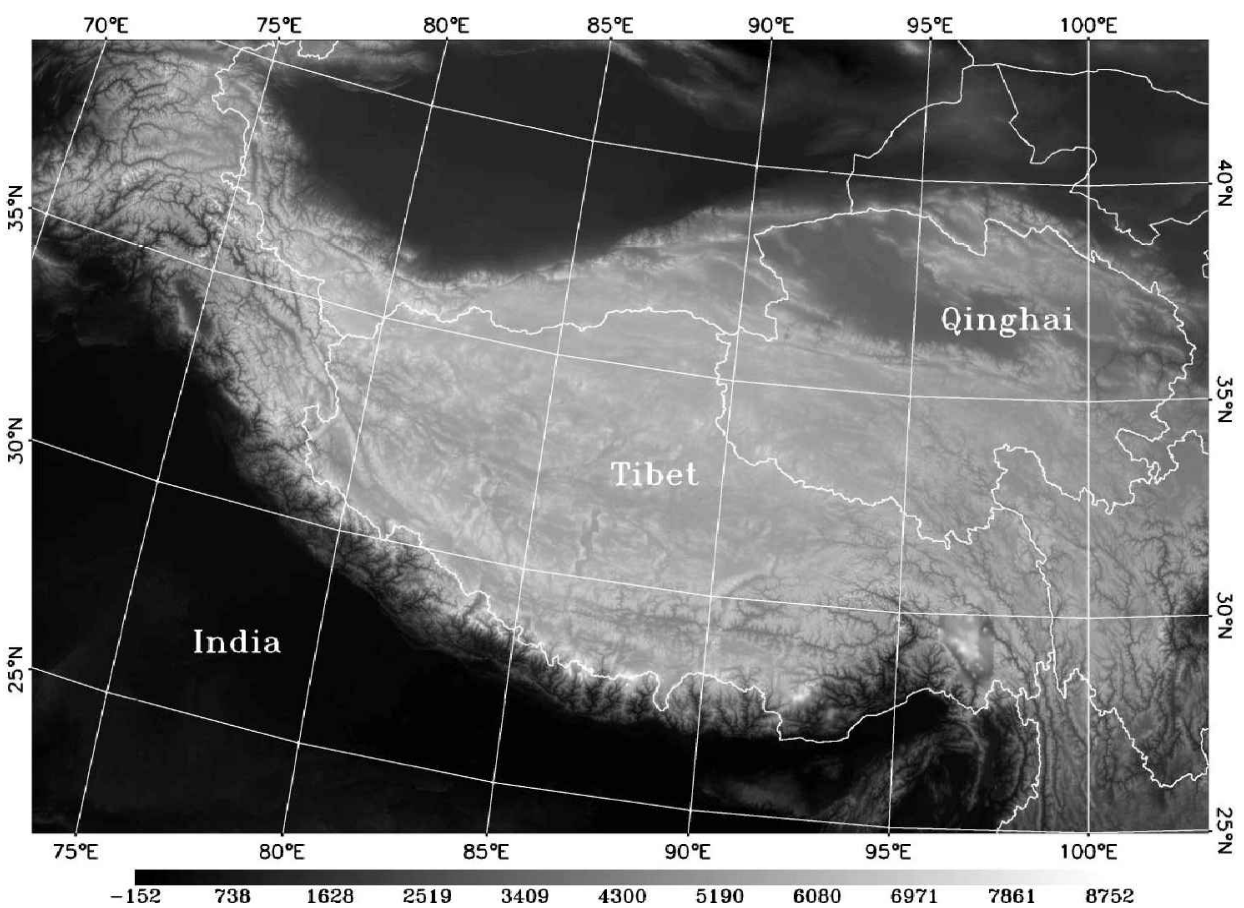

Figure 1. The digital elevation model (DEM) at 1-km resolution in the alpine region of Asia $\left(73^{\circ}-103^{\circ} \mathrm{E}\right.$ and $\left.25^{\circ}-40^{\circ} \mathrm{N}\right)$. The polygons in the map are the provincial boundaries of China.

land coverage with a minimum effect of cloud cover. Each pixel of VGT-S products represents a ground area of approximately $1 \mathrm{~km} \times 1 \mathrm{~km}$. The pixel brightness count in VGT-S products is the ground reflectance, as an atmospheric correction has been applied to raw VGT images, which takes the effects of ozone, aerosols and water vapour into consideration. For each month there are three 10-day composites: day 1-10, day 11-20 and day 21 to the last day of a month. The 10-day composite dataset includes four spectral bands (B0, B2, B3, MIR, see table 1) in 16-bit Digital Number (DN) values, and a quality flag file that contains information about cloud pixels.

Twenty-seven VGT-S10 products from 1-10 March 1999 to 21-30 November 1999 were available for this study. In image pre-processing, the DN of the VGT-S10 data was first converted to reflectance values using the equation and specific parameters provided within the datasets: real reflectance value $=\mathrm{a} \times \mathrm{DN}+\mathrm{b}$, where $\mathrm{a}=$ $0.0005, b=0.0$. The reflectance values of the four spectral bands were then used in the data analysis (see \$2.2). Second, cloud pixels in a VGT-S10 image were replaced with averaged reflectance values of non-cloud pixels within a $3 \times 3 \times 3\left(t_{1}, t, t_{+1}\right)$ space-time cube, based on the information of cloud pixels provided in the quality flag files. Therefore, in this study the VGT-S10 data from 11-20 March 1999 to 11-20 November 1999 (a time series of twenty-five 10-day composites) were used for snow/ice mapping. The VGT data are in Lambert Azimuthal Equal Area projection at $1-\mathrm{km}$ resolution, and cover the study area. The commercial image processing software ENVI (version 3.2) was used in this study. 
Table 1. A comparison in spectral bands and spectral reflectance values of snow and ice cover between Landsat TM and VEGETATION (VGT sensor) in SPOT 4. The spectral reflectance values of snow and ice cover are generated by re-sampling the spectral library of snow types from the Johns Hopkins University, using Landsat 5 TM spectral bandwidth and VGT spectral bandwidth. The commercial image processing software (ENVI version 3.2; Research System Inc.) provides the spectral library and the spectral re-sampling algorithm.

\begin{tabular}{|c|c|c|c|c|}
\hline \multirow[b]{2}{*}{ Optical sensors } & \multicolumn{4}{|c|}{ Spectral reflectance of snow and ice cover } \\
\hline & $\begin{array}{c}\text { Course granular } \\
\text { snow }\end{array}$ & $\begin{array}{l}\text { Medium granular } \\
\text { snow }\end{array}$ & $\begin{array}{c}\text { Fine granular } \\
\text { snow }\end{array}$ & Frost \\
\hline \multicolumn{5}{|l|}{ Landsat TM $(\mu \mathrm{m})$} \\
\hline \multicolumn{5}{|l|}{ TM1 $(0.45-0.52)$} \\
\hline TM2 $(0.52-0.60)$ & 0.969 & 0.979 & 0.989 & 0.993 \\
\hline TM3 $(0.63-0.69$ & 0.942 & 0.960 & 0.978 & 0.986 \\
\hline \multicolumn{5}{|l|}{ TM4 (0.76-0.90) } \\
\hline TM5 $(1.55-1.75$ & 0.032 & 0.080 & 0.238 & 0.411 \\
\hline $\begin{array}{l}\text { NDSI } \\
\text { (Hall et al. 1998,1995) }\end{array}$ & 0.94 & 0.85 & 0.61 & 0.41 \\
\hline $\begin{array}{l}\text { NDSII } \\
\text { (Xiao et al. 2001) }\end{array}$ & 0.94 & 0.85 & 0.61 & 0.41 \\
\hline \multicolumn{5}{|l|}{ VGT in SPOT4 $(\mu \mathrm{m})$} \\
\hline \multicolumn{5}{|l|}{ BO $(0.43-0.47)$} \\
\hline $\mathrm{B} 2(0.61-0.68)$ & 0.943 & 0.961 & 0.978 & 0.987 \\
\hline \multicolumn{5}{|l|}{ B3 $(0.78-0.890)$} \\
\hline MIR (1.58-1.75) & 0.024 & 0.065 & 0.211 & 0.385 \\
\hline NDSII & 0.95 & 0.87 & 0.64 & 0.44 \\
\hline
\end{tabular}

\subsection{Image analysis method for identification and mapping of snow/ice cover}

A number of earlier remote sensing studies have used Landsat TM data and explored various TM spectral bands in identifying and mapping snow cover (Hall et al. 1995, 1998, Boresjö Bronge and Bronge 1999, Sidjak and Wheate 1999). Hall et al. $(1995,1998)$ proposed the Normalized Difference Snow Index (NDSI). When using Landsat TM data, NDSI is calculated as the following equation:

$$
\mathrm{NDSI}=(\mathrm{TM} 2+\mathrm{TM} 5) /(\mathrm{TM} 2-\mathrm{TM})
$$

To determine whether a pixel is snow/ice or not, Hall et al. $(1995,1998)$ proposed a threshold method: if a pixel has NDSI $\geqslant 0.40$ and reflectance value of the near infrared band (NIR) $>0.11$, it is classified to be snow/ice cover.

In using TM data and ground radiometer measurements to classify ice and snowtype in the eastern Antarctic, Boresjö Bronge and Bronge (1999) found that the TM3/TM4 ratio is a simple tool for distinguishing between blue-ice and snow, and the TM3/TM5 ratio is a useful tool for enhancing snow grain-size variation. Given that the VGT sensor has red and mid-infrared spectral bands that are equivalent to TM3 and TM5 (table 1) and provides daily images of the land surface at 1-km resolution, Xiao et al. (2001) proposed a VGT-specific Normalized Difference Snow/Ice Index (NDSII) to map snow and ice cover. NDSII is calculated as the following equations:

$\mathrm{NDSII}=(\mathrm{TM} 3+\mathrm{TM} 5) /(\mathrm{TM} 3-\mathrm{TM} 5)$ when using Landsat TM data

$\mathrm{NDSII}=(\mathrm{B} 2+\mathrm{MIR}) /(\mathrm{B} 2-\mathrm{MIR})$ when using VGT data (see table 1$)$ 
The NDSII is similar to the NDSI proposed by Hall et al. $(1995,1998)$. In an earlier study, Xiao et al. (2001) compared NDSII and NDSI, using a Landsat 5 TM image (16 August 1996, WRS Path 132/Row 34) that covers the eastern part of Qilian Mountain in the Qinghai-Xizang (Tibet) Plateau in China. To determine whether a pixel is covered by snow/ice or not, the same thresholds proposed by Hall et al. $(1995,1998)$ were used, that is, if a pixel has NDSII $\geqslant 0.40$ or NDSI $\geqslant 0.40$ and reflectance value of the near-infrared band (NIR) $>0.11$, the pixel is classified to be snow/ice cover. The comparison showed that both NDSII and NDSI gave very similar estimates of the area and spatial distribution of snow/ice cover in the eastern Qilian Mountain of Qinghai-Xizang (Tibet) Plateau (Xiao et al. 2001). In this VGT data analysis we used NDSII and B3 (NIR) values, and adopted the same thresholds as in the earlier Landsat TM studies (Hall et al. 1995, 1998, Xiao et al. 2001): NDSII $\geqslant 0.40$ and band $\mathrm{B} 3$ (NIR) $>0.11$. Therefore, for each of the 25 composites, we first calculated NDSII and then applied the thresholds of NDSII and B3 to determine whether a pixel is snow/ice cover or not. A map of snow/ice cover versus non-snow/ice cover was generated for each of the 25 composites.

\subsection{Digital elevation model and long-term mean climate data}

In alpine environments, the spatial distribution of snow/ice cover may be correlated to elevation and topography. In order to qualitatively examine the relationship between snow/ice cover distribution and elevation, the Global Land One-kilometer Base Elevation (GLOBE) digital elevation dataset was used in this study, which was released by the NOAA National Geophysical Data Center (NDGC) in 1999 (also see the web site http://www.ngdc.noaa.gov/). The global digital elevation model (DEM) dataset was developed under the support of NOAA, the Committee on Earth Observation Satellites (CEOS) and International Geosphere and Biosphere Program's Data and Information System (IGBP-DIS). The dataset has a spatial resolution of 30 arc second (in a geographic projection). It is organized into 16 tiles for the world; and each tile has 10800 columns and 4800 or 6000 rows. The study area $\left(73^{\circ}-103^{\circ} \mathrm{E}\right.$ and $\left.25^{\circ}-40^{\circ} \mathrm{N}\right)$ is located within four tiles $(\mathrm{C}, \mathrm{D}, \mathrm{G}, \mathrm{H})$ of the global DEM dataset. These four tiles were re-projected from a geographical projection to Lambert Azimuthal Equal Area projection (1-km spatial resolution), using the nearest neighbour re-sampling method, and combined together into one data layer. The resultant DEM $(\mathrm{C}, \mathrm{D}, \mathrm{G}, \mathrm{H})$ data layer was subset to the study area, consistent with the area coverage of the VGT data (figure 1).

Spatial and temporal variations of temperature and precipitation may determine the spatial and temporal distribution of snow and ice cover in the alpine region. However, 1999 weather data for the study area are not available for this study. As an alternative, the long-term average monthly climate data from the Cramer and Leemans Climate database (W. Cramer, personal communication, 1995) was used. It is an update of the Leemans and Cramer climate database (Leemans and Cramer 1991) that was developed using records of about 18000 weather stations over the globe, and has a spatial resolution of $0.5^{\circ}$ in latitude and longitude. Monthly precipitation and temperature data for the study area were extracted from the global climate database. Monthly precipitations over a year were compared to determine which month has the largest precipitation for each of the $0.5^{\circ}$ pixels. This analysis of long-term average climate data provided information about the general patterns of climate in the alpine region, and is helpful for understanding the spatial and temporal distribution of snow and ice cover. 


\section{Results}

\subsection{Spatial distributions of NDSII and snow/ice cover}

As shown in figure 2, snow/ice cover has very high spectral reflectance values in visible bands (TM1, 2, 3), but very small reflectance values in the mid-infrared bands (figure 2). Among the four snow/ice cover types (frost, fine granular snow, medium granular snow and course granular snow), the differences in spectral reflectance are relatively small in visible bands but large in the mid-infrared (figure 2). Variations in grain sizes of snow affect spectral reflectance values of the red band (B2) and mid-infrared band (MIR) of the VGT sensor and consequently NDSII values (table 1). For the VGT sensor, NDSII values range from 0.44 for frost to 0.95 for coarse granular snow (table 1).

There are large spatial and temporal variations in NDSII values across the alpine region (figure 3). In 11-20 March 1999, high NDSII values $(\geqslant 0.40)$ were observed in most of the north-western part (e.g. Karakoram Range, Pamirs Plateau) of the alpine region and along the Himalaya Mountains (figure 3(a)). Although most of the eastern part of the alpine region had low NDSII values, there were relatively high NDSII values $(\geqslant 0.40)$ in its mountainous areas, including the Hengduan Shan, eastern Tanggula Shan, and eastern Nyainqentanglh a Shan mountains (see the area within a window of $94^{\circ}-97^{\circ} \mathrm{E}$ and $29^{\circ}-31^{\circ} \mathrm{N}$ in figure $3(a)$ ). The spatial patterns of NDSII values in 11-20 November 1999 are substantially different from those in 11-20 March 1999 (figure 3). High NDSII values $(\geqslant 0.40)$ were observed in a large portion of the eastern part (Tanggula Shan and Nyainqentanglha Shan mountains) of the alpine region in 11-20 November 1999 (figure 3(b)).

The thresholds of NDSII $\geqslant 0.40$ and B3 (NIR) $>0.11$ were used to identify snow and ice cover in each of the 25 images from 11-20 March 1999 to 11-20 November

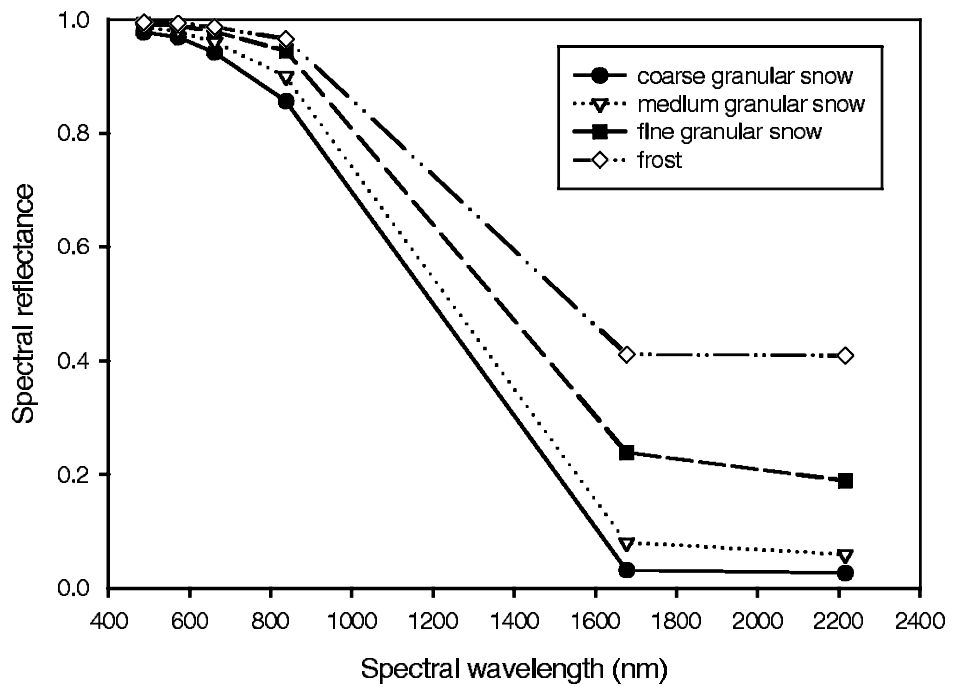

Figure 2. Spectral reflectance of four types of snow and ice cover, as measured according to Landsat 5 TM spectral bandwidth. It is based on the spectral library for snow and ice covers from the Johns Hopkins University. We conducted spectral re-sampling of the spectral library, using Landsat 5 TM spectral bandwidth. The ENVI software (version 3.2; Research System Inc.) provides the spectral library and spectral re-sampling algorithm. 


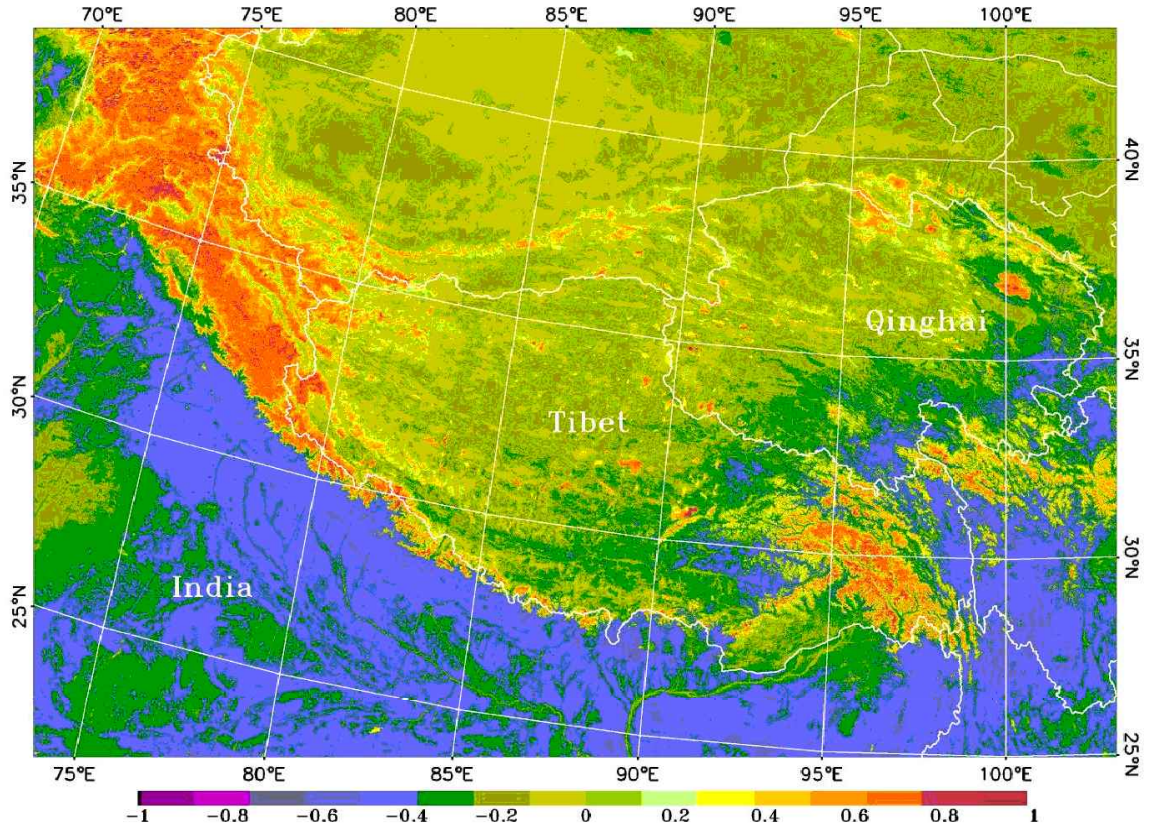

(a)

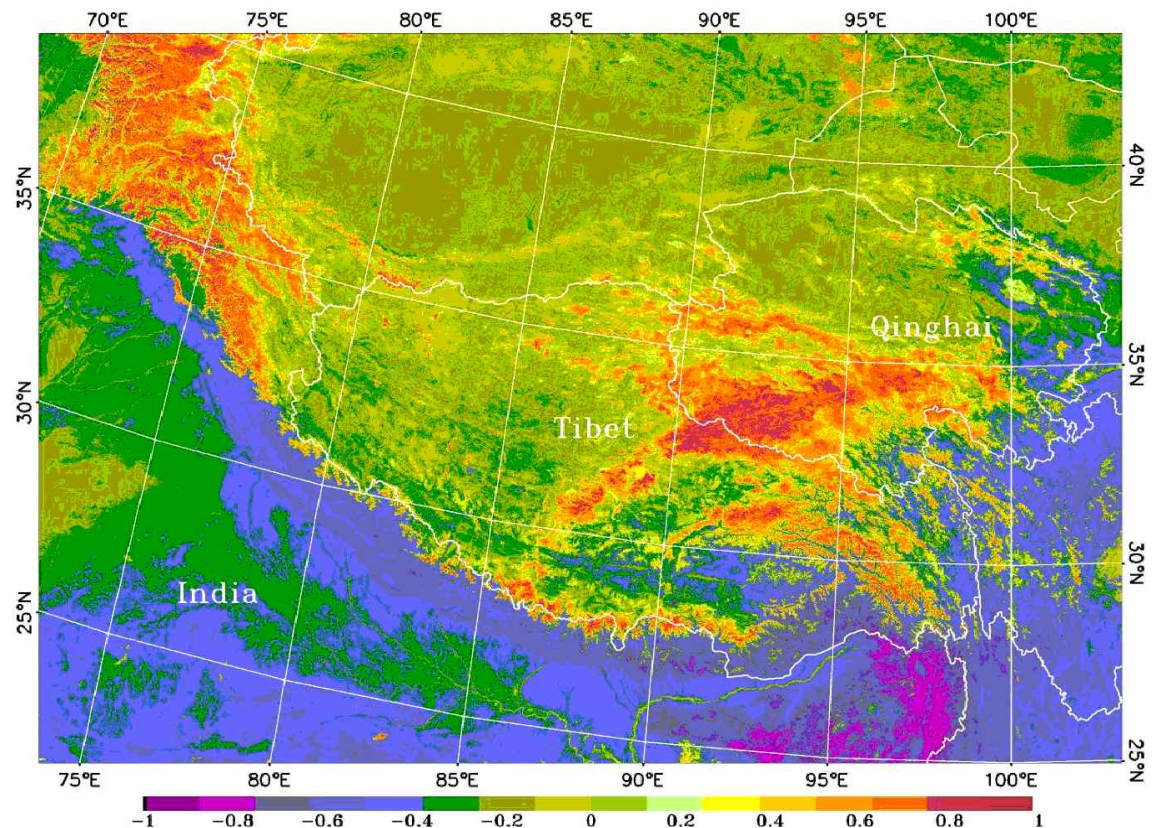

(b)

Figure 3. Spatial distributions of the normalized difference snow/ice index (NDSII) values in the alpine region of Asia $\left(73^{\circ}-103^{\circ} \mathrm{E}\right.$ and $\left.25^{\circ}-40^{\circ} \mathrm{N}\right)$. (a) 11-20 March 1999, (b) 11-20 November 1999. 
1999. In 11-20 March 1999, snow/ice cover was concentrated in the north western part of the alpine region (figure $4(a)$ ). There was also a small area of snow and ice cover in the mountainous area (around $30^{\circ} \mathrm{N}$ and $95^{\circ} \mathrm{E}$ in figure $4(a)$ ) in the south eastern part of the alpine region, where the largest monthly precipitation usually occurs in April under the control of the summer plateau monsoon (Tang 1998). In 11-20 November 1999 there was much more snow/ice cover in the eastern part than in the western part of the alpine region (figure $4(b)$ ). In addition, the Qilian Shan Mountain (around $98^{\circ} \mathrm{E}$ and $38^{\circ} \mathrm{N}$ in figure $4(b)$ ), which is the northern boundary of the Qinghai-Xizang (Tibet) Plateau, was also covered by snow/ice.

As expected, the spatial patterns of NDSII and snow/ice cover in 11-20 March 1999 were closely correlated to the plateau monsoon climate and its precipitation pattern in the alpine region, as discussed in detail by Tang and Reiter (1984) and Tang (1993, 1998). Climate in the alpine region is controlled primarily by plateau monsoon climate (Tang and Reiter 1984, Tang 1993). The western part (e.g. Afghanistan) of the alpine region is generally wet in winter but dry in summer, while the eastern part of the alpine region is relatively dry in winter but wet in summer (Tang 1998). The winter plateau monsoon travels from the Arabian Peninsula (east of $60^{\circ} \mathrm{E}$ ) in a north-east direction into the western part of the alpine region. Along the way, monthly precipitation reaches its height from December in the eastern Arabian Peninsula to April in the very western end of the Qinghai-Xizang (Tibet) Plateau (Tang 1998; also see figure 5). Because of the high elevation (figure 1) and the resultant low temperature, a large portion of precipitation in the north-western part of the alpine region was snow/ice, as indicated by the NDSII map (figure 3(a)) and snow/ice cover map (figure $4(a)$ ).

In addition to the plateau monsoon climate system (Tang and Reiter 1984, Tang 1993, 1998), elevation also contributes significantly to the spatial distribution of snow/ice cover in the alpine region (figure 6; figure 1). The study area has a minimum elevation of $1 \mathrm{~m}$ and a maximum elevation of $8742 \mathrm{~m}$ (figure 1). The elevation histogram (figure 6) shows that approximately $50 \%$ of the study area has an elevation of $\geqslant 3600 \mathrm{~m}$. Figure 6 compares snow/ice cover distributions along the elevation gradient for 11-20 March, 1-10 August and 11-20 November 1999. Out of 0.46 million $\mathrm{km}^{2}$ of snow/ice cover in 11-20 March 1999 , about $89 \%$ of snow/ice cover was located in areas where the elevation is greater than $3800 \mathrm{~m}$. By comparison, out of 0.60 million $\mathrm{km}^{2}$ of snow/ice cover in $11-20$ November 1999 , about $89 \%$ of snow/ice cover was located in areas where the elevation is greater than $4300 \mathrm{~m}$. This difference in snow/ice cover along the elevation gradient is due to the fact that in 11-20 March 1999 there was more snow/ice cover in the western part of the alpine region where the elevation is lower than the eastern part of the alpine region (figure 1). In summer, the air temperature is high and snow/ice cover occurs mostly in very high altitude areas. About $89 \%$ of the 0.05 million $\mathrm{km}^{2}$ snow/ice cover in 1-10 August 1999 was located in areas where the elevation is greater than $4900 \mathrm{~m}$ (figure 6).

\subsection{Seasonal dynamics of snow and ice cover}

The total area of snow/ice cover in the alpine region varied substantially over the seasons in 1999 (figure 7). The total area of snow/ice cover in 11-20 March 1999 was estimated to be 0.46 million $\mathrm{km}^{2}$, accounting for $9.9 \%$ of the total land area in the alpine region. As the season progressed from spring into summer, the air temperature increased and snow/ice melted, resulting in a gradual decrease in the total 


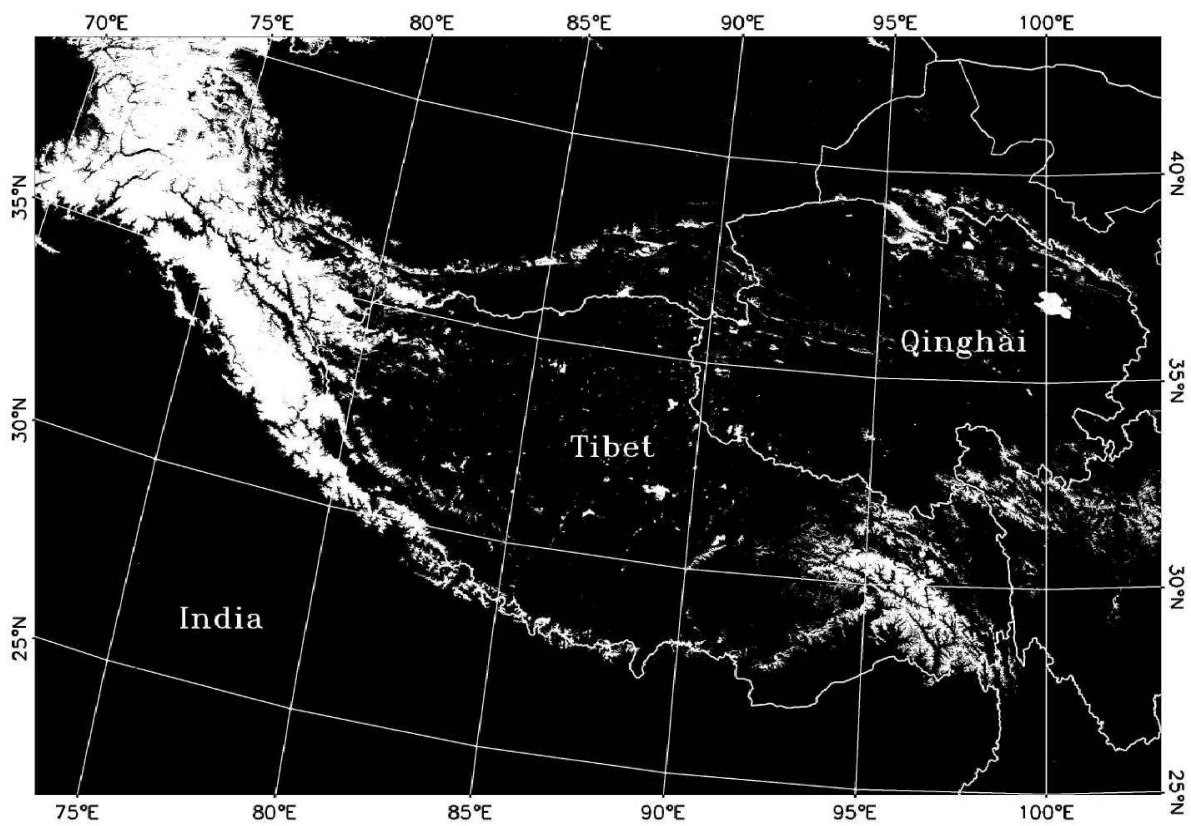

(a)

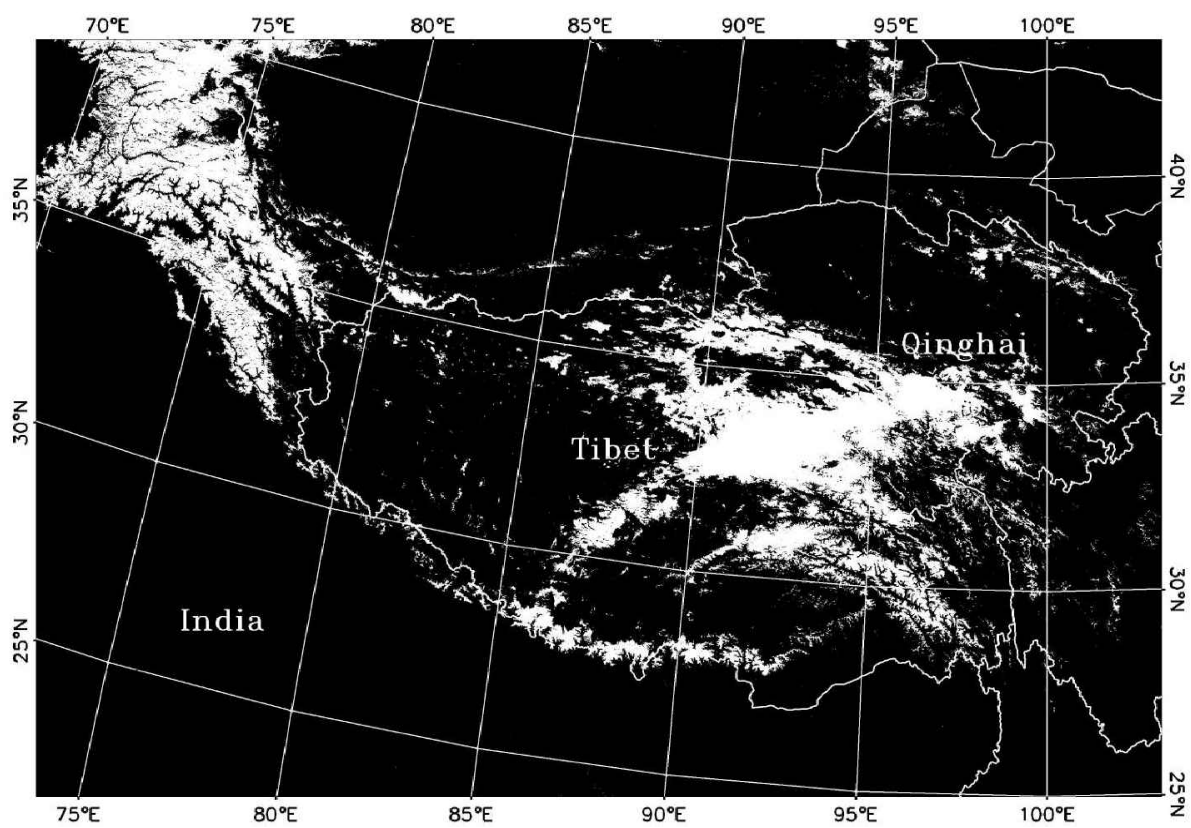

(b)

Figure 4. Spatial distributions of snow and ice cover in the alpine region of Asia $\left(73^{\circ}-103^{\circ} \mathrm{E}\right.$ and $25^{\circ}-40^{\circ} \mathrm{N}$ ). Snow/ice cover is represented as white colour. (a) 11-20 March 1999, (b) 11-20 November 1999 . 


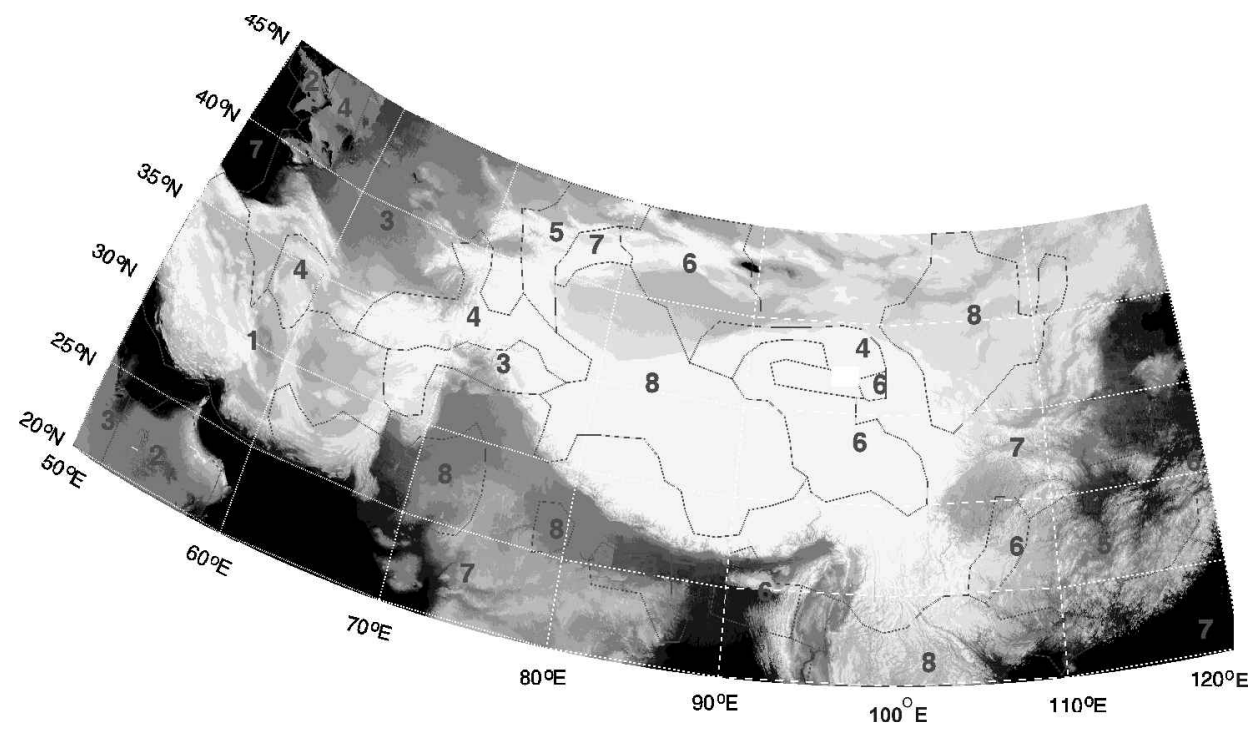

Figure 5. Spatial distribution of months that have the largest monthly precipitation in a year; generated using long-term averaged monthly precipitation data from the IIASA Climate database at $0.5^{\circ}$ by $0.5^{\circ}$ spatial resolution (Wolfgang Cramer, personal communication, 1995). The number in a polygon represents the month that has the largest monthly precipitation in a year (e.g. January $=1$, February $=2, \ldots$, December $=12$ ). The grey-scale background image is the digital elevation model (DEM) at 1-km spatial resolution.

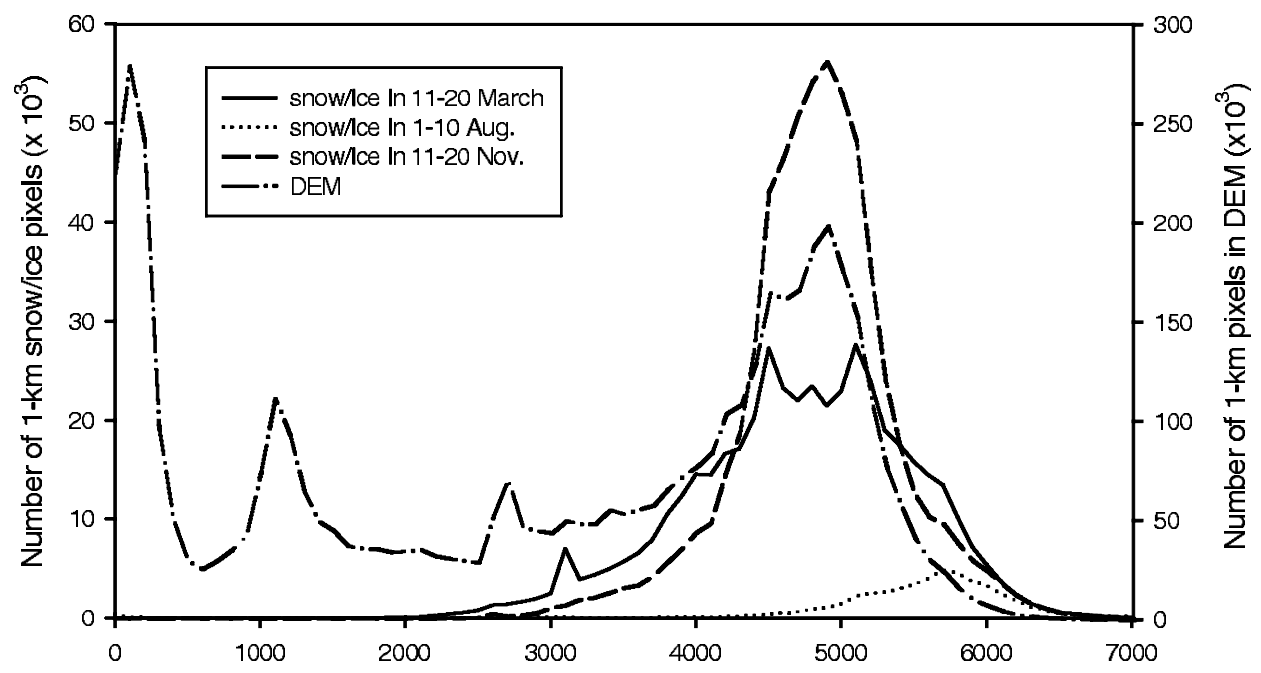

Elevation (100-m increment) from the 1-km digital elevation model (DEM)

Figure 6. The frequency distribution histograms of elevation and VGT-derived snow/ice pixels along the elevation gradient in the alpine region of Asia $\left(73^{\circ}-103^{\circ} \mathrm{E}\right.$ and $25^{\circ}-40^{\circ} \mathrm{N}$ ). The elevation gradient is in $100-\mathrm{m}$ bins. 


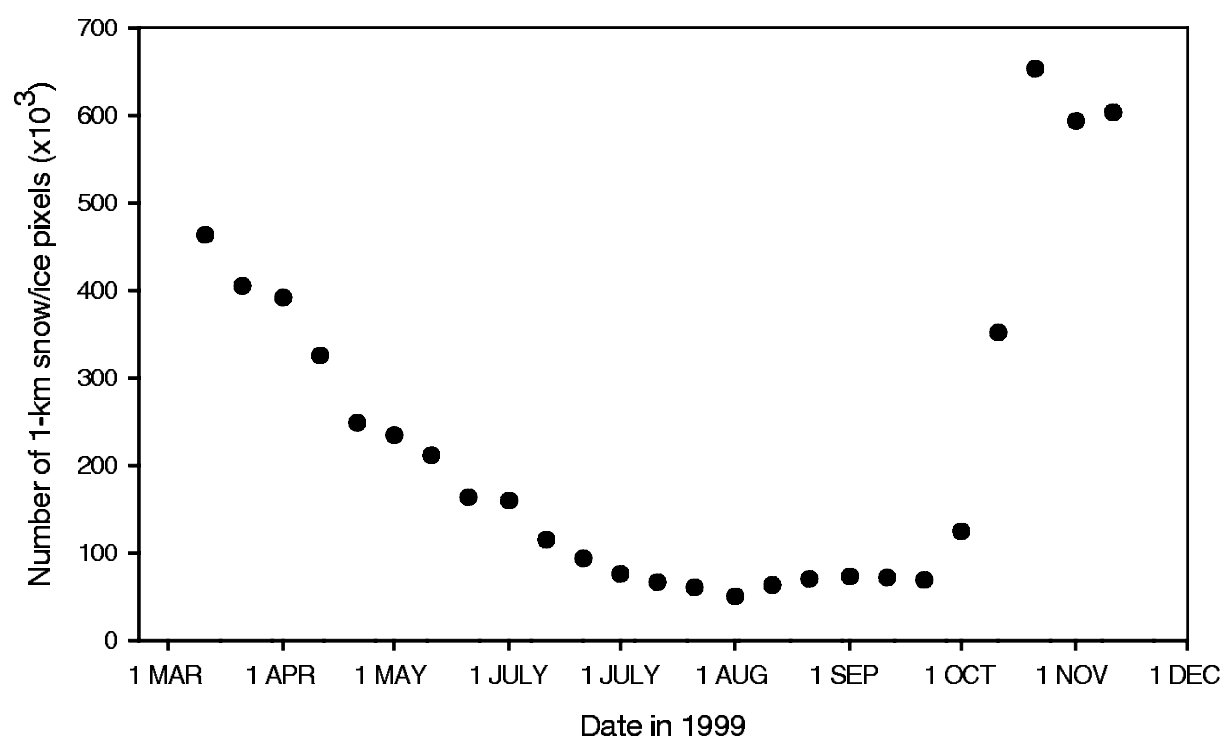

Figure 7. Seasonal dynamics of total area of snow and ice cover over the period 11-20 March 1999 to 11-20 November 1999 (twenty-five 10-day composites) in the alpine region of Asia $\left(73^{\circ}-103^{\circ} \mathrm{E}\right.$ and $\left.25^{\circ}-40^{\circ} \mathrm{N}\right)$. Each pixel has an area of $1 \mathrm{~km}^{2}$.

areas of snow/ice cover in the alpine region (figure 7). In 1-10 August 1999, the total area of snow/ice cover reached its lowest level (only 0.05 million $\mathrm{km}^{2}$ ). In mid- and late-August there were slight increases in the total areas of snow/ice cover (figure 7), which is most likely to be attributed to the summer plateau monsoon climate, as discussed in Tang (1993, 1998). The inner branch of the summer plateau monsoon continues travelling towards the north and west along the Himalaya Mountains, and in August it brings the largest monthly precipitation in the mid-range of the Himalaya Mountains (Tang 1993). In addition, the outside branch of the summer plateau monsoon, which originates to the east of $107^{\circ} \mathrm{E}$, moves into the alpine region, and the north-eastern part of the Qinghai-Xizang Plateau usually has its largest monthly precipitation in August (Tang 1993). Therefore, abundant precipitation in August (due to the summer plateau monsoon climate) and cold temperatures (due to high elevations) may result in some new snow/ice cover in the eastern alpine region. There was little change in total area of snow/ice cover in September 1999 (figure 7). In the eastern part of the alpine region, the snow season begins in October (Zhen and $\mathrm{Li}$ 1998), in part owing to decreases of air temperature in the alpine region. The total area of snow/ice cover in the alpine region increased rapidly in October (figure 7), and reached 0.60 million $\mathrm{km}^{2}$ snow/ice cover by $11-20$ November 1999 , accounting for $11.4 \%$ of the total land area of the alpine region.

We calculated the VGT-derived frequency of snow/ice cover events (ranging from 0 to 25$)$ for all the pixels $\left(1 \mathrm{~km}^{2}\right.$ each pixel $)$ in the alpine region over the period of 11-20 March 1999 to 11-20 November 1999 (a total of 25 composites). About 25\% of the alpine region $\left(73^{\circ}-103^{\circ} \mathrm{E}\right.$ and $\left.25^{\circ}-40^{\circ} \mathrm{N}\right)$ was covered by snow/ice in at least one of 25 composites from 11-20 November 1999 to 11-20 March 1999. As indicated by the frequency histogram of snow/ice cover events in the alpine region (figure 8), among those areas in the alpine region that had snow/ice cover, the majority (about $71 \%$ ) of pixels were covered by snow/ice in one to four composites (figure 8). It was 


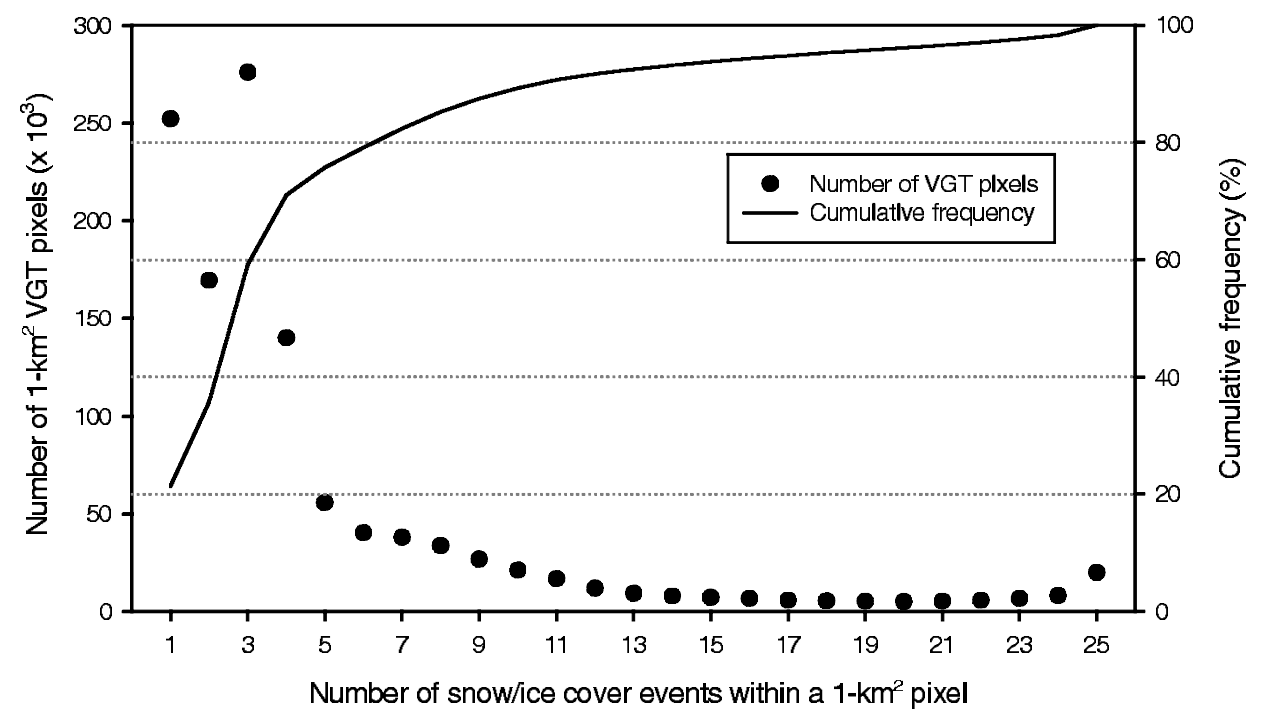

Figure 8. The frequency distribution and cumulative frequency histograms of snow and ice cover events in the alpine region of Asia $\left(73^{\circ}-103^{\circ} \mathrm{E}\right.$ and $\left.25^{\circ}-40^{\circ} \mathrm{N}\right)$ over the period 11-20 March 1999 to 11-20 November 1999 (twenty-five 10-day composites). Each pixel has an area of $1 \mathrm{~km}^{2}$.

estimated 0.15 million pixels $\left(\mathrm{km}^{2}\right)$ had snow/ice cover in 10 or more composites, and that 0.05 million pixels $\left(\mathrm{km}^{2}\right)$ had snow/ice cover in 20 or more composites. The spatial distribution of snow/ice cover frequency varied substantially across the alpine region over the period from 11-20 March 1999 to 11-20 November 1999. A large number of pixels in the north-western part (e.g. Pamirs Plateau, Karakoram Range, western Kulun Mountain) of the alpine region had high frequencies of snow/ice cover events (figure 9). By comparison, the eastern part of the alpine region had fewer pixels with a high frequency of snow/ice cover, which may indicate a much faster dynamic of snowfall, accumulation and snowmelt in the eastern part (figure 9).

\section{Discussion}

The results of this VGT-based analysis show that there were large spatial and temporal variations in NDSII values and snow/ice cover in the alpine region. Large variations of NDSII values between 0.4 and 1.0 (figure 3 ) may to some degree, be correlated to snow/ice cover types or grain sizes of snow (see figure 2 and table 1; Boresjö Bronge and Bronge 1999). However, in this study no field observations of snow/ice cover (timing, duration and location, granular size) were available for developing the quantitative relationship between NDSII and the snow/ice cover types and variations in grain sizes of snow. Further field data collection and analysis are needed for validation of VGT-based NDSII, including its thresholds for identifying snow/ice cover and the relationship with grain sizes of snow.

The spatial patterns and seasonal dynamics of NDSII and snow/ice cover in the alpine region are closely related to the plateau monsoon climate and its precipitation patterns (Tang 1984, 1993, 1998). Other studies that used AVHRR data also showed that there were large spatial and temporal (both seasonal and interannual) variations in snow cover in the alpine region (Zhen and Li 1998). Zhen and Li (1998) used weekly data of snow cover from the NOAA NESDIS database (see Robinson et al. 


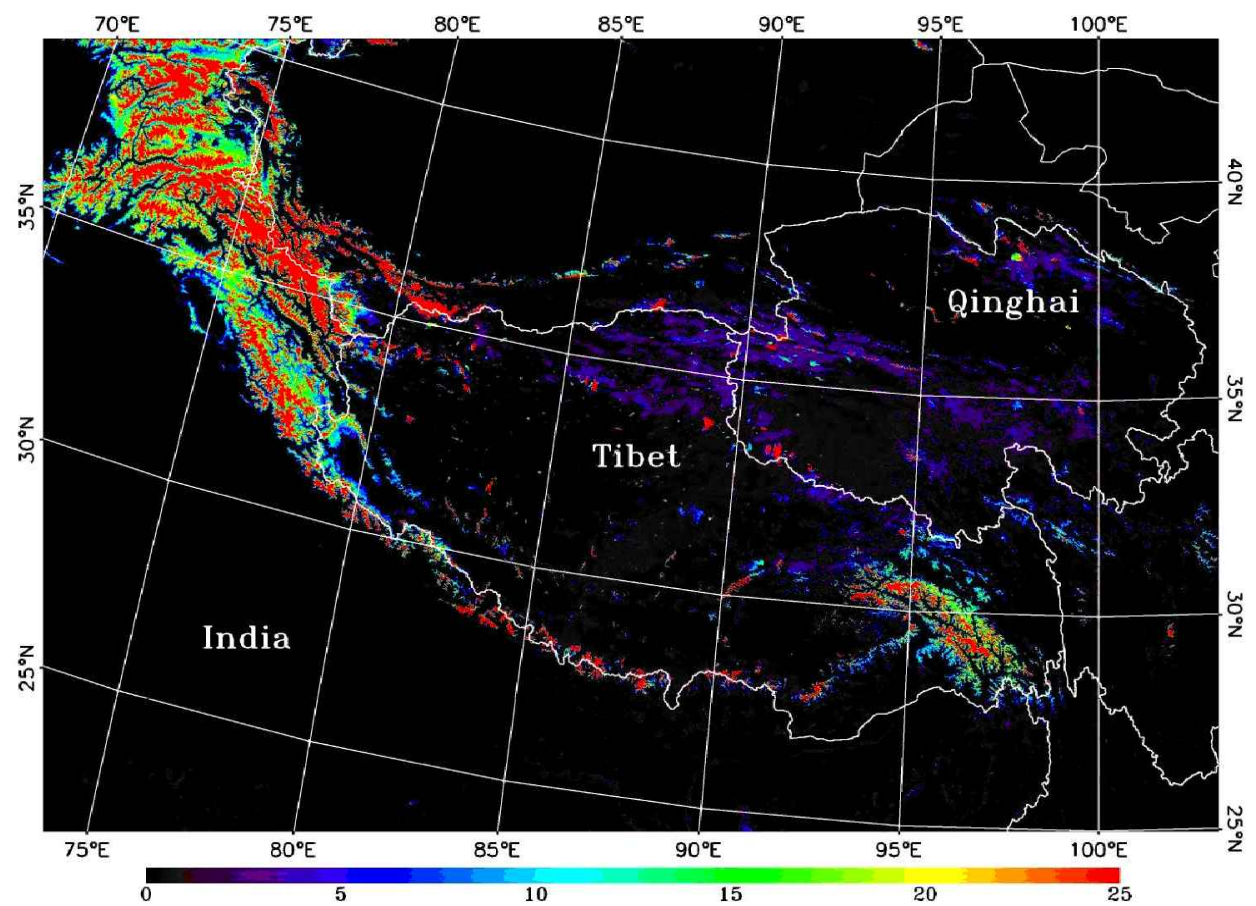

Figure 9. Spatial distributions of snow and ice cover frequency over the period 11-20 March 1999 to 11-20 November 1999 (twenty-five 10-day composites) in the alpine region of Asia $\left(73^{\circ}-103^{\circ} \mathrm{E}\right.$ and $\left.25^{\circ}-40^{\circ} \mathrm{N}\right)$. The number representing snow/ice cover frequency for a pixel ranges from 0 (no snow cover) to 25 (always snow/ice cover).

1993), which has a very coarse spatial resolution (ranging from $20428 \mathrm{~km}^{2}$ to $27732 \mathrm{~km}^{2}$ in the study area), to estimate monthly areas of snow cover in the study area $\left(73^{\circ}-103^{\circ} \mathrm{E}\right.$ and $\left.25^{\circ}-40^{\circ} \mathrm{N}\right)$ from 1981 to 1991 . The AVHRR-based monthly estimates of snow/ice cover in March over the period 1981-1991 ranged from 0.78 million $\mathrm{km}^{2}$ in 1984 to 2.43 million $\mathrm{km}^{2}$ in 1983 , with a mean of 1.28 million $\mathrm{km}^{2}$ (Zhen and Li 1998). The VGT-based estimate $\left(0.46\right.$ million $\left.\mathrm{km}^{2}\right)$ of snow/ice cover in 11-20 March 1999 was much smaller than the AVHRR-based monthly estimate of snow cover. Zhen and Li (1998) also estimated that total area of snow/ice cover in November over the period 1981-1991 ranged from 0.75 million $\mathrm{km}^{2}$ in 1988 to 2.14 million $\mathrm{km}^{2}$ in 1985 , with a mean of 0.78 million $\mathrm{km}^{2}$. The VGT-based estimate ( 0.60 million $\left.\mathrm{km}^{2}\right)$ of snow/ice cover in 11-20 November 1999 was much lower than the AVHRR-based monthly estimate of snow cover. Because no VGT data for December, January and February of 1999 were available in this study, there are no VGT-based estimates of snow/ice cover for winter season in the alpine region. According to Zhen and Li (1998), the total areas of snow cover in the study area $\left(73^{\circ}-103^{\circ} \mathrm{E}\right.$ and $\left.25^{\circ}-40^{\circ} \mathrm{N}\right)$ over the period 1981-1991 were largest in January, ranging from 1.38 million $\mathrm{km}^{2}$ in 1985 to 2.46 million $\mathrm{km}^{2}$ in 1989 , with a mean of 1.85 million $\mathrm{km}^{2}$. The AVHRR-based dataset is likely to overestimate snow cover owing to the difficulty in visual separation of cloud cover and snow as well as its coarse spatial resolution. 
Large-scale validation of snow/ice cover derived from VGT data is a difficult and challenging task. In general there are three approaches for validation of snow/ice cover products: (1) records of snow from weather stations; (2) field surveys; and (3) fine resolution image data (e.g. Landsat 7 ETM +) acquired in the same timeframe as the VGT data. In the alpine region, there are few weather stations, and extensive field surveys of snow/ice cover in a timely fashion were too costly to be carried out in 1999. Because of budget limitations, we were not able to carry out a systematic validation of VGT-derived snow/ice cover with a large amount of Landsat 7 ETM + images. We obtained browse images of two Landsat 7 ETM + scenes (WRS $138 / 36$ and $138 / 37$, covering the areas of $32^{\circ}-35^{\circ} \mathrm{N}$ and $91^{\circ}-93^{\circ} \mathrm{E}$ in figures 3 and 4) on 28 September 1999 and 30 October 1999. Through visual interpretation of the ETM + browse images, we observed that there were only small areas of snow/ice cover on 28 September 1999, while there was almost complete coverage of snow/ice cover in the ETM + browse images on 30 October 1999. The snow/ice cover dynamics represented in these ETM + browse images is consistent with VGT composite data from 21-31 September 1999 and 21-30 October 1999.

The estimates of snow/ice cover in the alpine region from the 1-km VGT data have some uncertainty. One major source of uncertainty is the effect of complex topography in the alpine region (see figures 1 and 6). Solar elevation and solar azimuth angle vary over time, and the complex topography causes enhanced spatial-temporal variations in illumination of the land surface and shadow extent and patterns. In the VGT mapping approach, NSDII is a ratio variable using the reflectance values of the red and mid-infrared bands, and it may reduce, to some degree, the effects of illumination variations. However, in areas of very dark shadow there will be no information, resulting in an underestimation of snow/ice cover. Furthermore, the VGT mapping approach also uses reflectance values of the nearinfrared band as a second criterion for identifying snow/ice cover, and thus it is sensitive to variations in illumination and shadow extent and patterns. Therefore, further studies are needed to quantify the spatial-temporal variations in shadow extent and patterns as well as its consequences on snow/ice cover mapping. Another major source of uncertainty comes from the NDVI maximum value compositing (MVC) method that is used for the selection of near-nadir pixels within a 10-day period in standard VGT-S10 (10-day synthetic product). In VGT-S10, it is possible that a pixel with no snow will be selected during the 10-day period, although snow cover may exist on some of the 10-days; this scenario would result in an underestimation of snow cover. Therefore, the VGT-S1 (daily synthetic product) data are needed to provide more accurate estimates of snow/ice cover and to reduce the uncertainties of snow/ice cover estimates from the VGT-S10 data.

This study in the alpine region of Asia provides a large-scale case study for exploring the potential of the VGT-based NDSII approach (Xiao et al. 2001) in an effort to develop a simple and automatic tool for operational large-scale observation and monitoring of snow and ice cover in alpine environments. Since the launch of SPOT 4 in March 1998, multi-temporal VGT data for the globe have been accumulated and synthesized for atmospheric correction and geometric correction. Application of the VGT-based NDSII approach to the global VGT daily and/or 10-day synthetic data products (VGT-S1 and VGT-S10) could provide an improved dataset of snow/ice cover over AVHRR. It will also serve as a complementary dataset for the new global snow cover dataset that is under development from daily data of the Moderate Resolution Imaging Spectroradiometer (MODIS) sensor, using the 
NDSI-based approach (Hall et al. 1995, 1998). An improved dataset that characterizes the spatial distribution and seasonal dynamics of snow and ice cover in the world would greatly improve large-scale climate and hydrological modelling as well as water resource management.

\section{Acknowledgment}

This study was supported by a project from the US NASA Earth Observing System (EOS) Interdisciplinary Science Program and a project from the US Multiagency Joint Program on Terrestrial Ecology and Global Change (TECO). We thank Charles Vörösmarty for his review on the earlier draft of the manuscript. Drs Qin and Shen are visiting scientists at the Complex Systems Research Center, Institute for the Study of Earth, Oceans and Space, University of New Hampshire, under the support of the Chinese Academy of Sciences. We thank Michael Routhier and Stanley Glidden for their help in generating precipitation graphs in the study region. We also thank the anonymous reviewers for their insightful comments and suggestions on the earlier version of the manuscript.

\section{Reference}

Boresjö Bronge, L. B., and Bronge, C., 1999, Ice and snow-type classification in the Vestfold Hills, East Antarctica, using Landsat TM data and ground radiometer measurements. International Journal of Remote Sensing, 2, 225-240.

Cline, D. W., and Carroll, T. R., 1999, Operational automated production of daily, highresolution, cloud-free snow cover maps of the continental U.S. Journal of Geophysical Research, 104, 19631-19644.

Goodison, B. E., Brown, R. D., and Crane, R. G., 1999, Cryospheric systems. In EOS Science Plan: The State of Science in the EOS Program, edited by M. D. King (NASA), pp. 261-307.

Hall, D. K., Foster, J. L., Verbyla, D. L., and Klein, A. G., 1998, Assessment of snowcover mapping accuracy in a variety of vegetation-cover densities in central Alaska. Remote Sensing of Environment, 66, 129-137.

Hall, D. K., Riggs, G. A., and Salomonson, V. V., 1995, Development of methods for mapping global snow cover using moderate resolution imaging spectroradiometer data. Remote Sensing of Environment, 54, 127-140.

Ives, J. D., and Messerli, B., 1999, AD 2002 Declared by United Nations as "International Year of the Mountains". Arctic, Antarctic and Alpine Research, 3, 211-213.

Leemans, R., and Cramer, W. P., 1991, The IIASA climate database for land areas on a grid with $0.5^{\circ}$ resolution, Res. Rep. RR-91-18, 60 pp., International Institute for Applied System Analysis, Laxenburg, Austria.

Ramsay, B., 1998, The interactive multisensor snow and ice mapping system. Hydrological Processes, 12, 1537-1546.

Robinson, D. A., Dewey, K. F., and Heim, R. R., 1993, Global snow cover monitoring. an update. Bulletin of American Meteorological Society, 74, 1689-1696.

Romanov, P., Gutman, G., and Csiszar, I., 2000, Automated monitoring of snow cover over North America with multi-spectral satellite data. Journal of Applied Meteorology (in press).

Sidjak, R. W., and Wheate, R. D., 1999, Glacier mapping of the Illecillewaet icefield, British Columbia, Canada, using Landsat TM and digital elevation data. International Journal of Remote Sensing, 2, 273-284.

TANG, M., 1993, Some advances in plateau monsoon climate research. Plateau Meteorology, 1, 95-101 (in Chinese).

TANG, M., 1998, Formation, evolution and fluctuation of plateau monsoon. In Contemporary Climatic Variations over Qinghai-Xizang (Tibetan) Plateau and Their Influences on Environments, edited by M. Tang, G. Cheng and Z. Lin (Guangzhou, China: Guangdong Science and Technology Press), pp. 161-183 (in Chinese). 
TAng, M., and ReITER, E. R., 1984, Plateau monsoons in the Northern Hemisphere. Monthly Weather Review, 4, 617-637.

XIAo, X., Shen, Z., and QIn, X., 2001, Assessing the potential of VEGETATION sensor data for mapping snow and ice cover: A normalized difference snow and ice index. International Journal of Remote Sensing, 22, 2479-2487.

Xu, H., Bailey, J. O., Barrett, E. C., and Kelly, R. E. J., 1993, Monitoring snow area and depth with integration of remote sensing and GIS. International Journal of Remote Sensing, 14, 3259-3268.

ZHEN, Q., and LI, Z., 1998, Remote sensing monitoring of glaciers, snow and lake ice in Qinghai-Xizang (Tibetan) Plateau. In Contemporary Climatic Variations over QinghaiXizang (Tibetan) Plateau and Their Influences on Environments, edited by M. Tang, G. Cheng and Z. Lin (Guangzhou, China: Guangdong Science and Technology Press), pp. 279-308 (in Chinese). 